\title{
TRIBUTAÇÃO DAS EXPORTAÇÕES NO PROCESSO DE REGIONALIZAÇÃO E INTEGRAÇÃO ECONÔMICA DO MERCOSUL E DA UNASUL
}

Maria de Fátima Ribeiro

Doutora em Direito Tributário pela PUC - São Paulo. Professora do Programa de Mestrado em Direito da UNIMAR - Marília - São Paulo - Brasil.

Thais Bernardes MaganhinI

Doutoranda em Direito pela PUC - São Paulo. Mestre em Direito pela UNIMAR. Professora da Universidade Federal de Rondônia - UNIR.

\section{Resumo}

Como o Código Aduaneiro do MERCOSUL - CAM aprovado pela Decisão CMC no 27/10 não dispóe sobre a incidência de imposto de exportação, é possível aos Estados Partes aplicar os direitos de exportação intrazona? Se o CAM não proíbe expressamente, é possível os Estados recorrerem para a incidência do tributo? O Código Aduaneiro prevê expressamente que não se aplica às operações de exportação (art. 157-4), e, sim somente para a importação, destacando que normas regulamentares, em momento oportuno, tratarão da questão. Há com isso, certa inquietude uma vez que a interpretação dos artigos do CAM pode gerar outros desdobramentos que teráo seus reflexos no desenvolvimento dos países do Bloco e consequentemente dificultará o seu processo de integração. O presente artigo tem como objetivo apresentar consideraçôes sobre o Código Aduaneiro do MERCOSUL - CAM, em especial sobre a exportação, levando em consideração a possibilidade da extensão dos estudos alcançarem os demais países que integram a UNASUL. A aprovação do Código Aduaneiro constitui um instrumento de fundamental importância para a concretização da União Aduaneira uma vez que uniformiza as normas e procedimentos aduaneiros dentro do bloco, possibilitando maior segurança jurídica. Dessa forma, poderá ser verificada a importância do CAM para o processo de regionalização e integração econômica com os impactos que poderá provocar para o desenvolvimento do MERCOSUL e possivelmente para a UNASUL. A análise passará pela literatura jurídica brasileira e dos referidos Blocos, utilizando-se o método dedutivo.

\section{Palavras-chave}

Exportação; MERCOSUL; UNASUL; Código Aduaneiro. 


\section{Resumen}

A medida que el Código Aduanero del MERCOSUR - CAM aprobado por la Decisión CMC No 27/10 no prevé la incidencia de impuesto a la exportación, es posible que los Estados Partes para poner en práctica los derechos de exportación intrazona? Si la CAM no prohíbe expresamente que es posible los Estados recurrir a la incidencia del impuesto? El Código Aduanero establece expresamente que no se aplica a las operaciones de exportación (art. 157-4), y sí sólo para la importación, y señaló que los reglamentos, en su momento, abordarán el tema. Allí, un poco de ansiedad ya que la interpretación de los artículos CAM puede generar otros acontecimientos que tendrán sus consecuencias en el desarrollo de los países del bloque y en consecuencia dificultar el proceso de integración. Este artículo tiene como objetivo presentar las consideraciones sobre el Código Aduanero del MERCOSUR - CAM, sobre todo en la exportación, teniendo en cuenta la posibilidad de estudios de extensión lleguen a los otros países de la UNASUR. La aprobación del Código Aduanero es un instrumento muy importante para la implementación de la unión aduanera, ya que estandariza las normas y procedimientos aduaneros dentro del bloque, lo que permite una mayor seguridad jurídica. Por lo tanto, se puede verificar la importancia de la CAM con el proceso de regionalización y la integración económica con los impactos que podrían resultar en el desarrollo del MERCOSUR y posiblemente UNASUR. El análisis incluirá la literatura jurídico brasileño y de estos bloques , utilizando el método deductivo.

\section{Palabras clave}

Exportaciones; MERCOSUR; UNASUR; Código Aduanero.

\section{Introdução}

É de fundamental importância destacar, inicialmente, a necessidade do fortalecimento e aprofundamento do processo de integração na América do Sul. Essa integração econômica regional é um dos instrumentos à disposição dos países da regiáo da luta contra a pobreza, para avançar no seu desenvolvimento econômico e social, bem como buscar uma melhor qualidade de vida de seus povos.

Com o ingresso do Brasil na UNASUL - União de Nações Sul-americanas ${ }^{1}$, também é preciso considerar que no marco do Tratado constitutivo, a integração sul-americana deve ser alcançada por meio de um processo inovador, que inclua todas as conquistas e

1 Criada em 23 de maio de 2008 em Brasília, com a participação dos seguintes membros: Argentina, Bolívia, Brasil, Chile, Colômbia, Equador, Guiana, Paraguai, Peru, Suriname, Uruguai e Venezuela. 
avanços obtidos pelo MERCOSUL - Mercado Comum do Sul, assim como a experiência do Chile, Guiana e Suriname, avançando além da convergência desses processos. O artigo $3^{\circ}$ do Tratado da UNASUL elenca objetivos específicos, dentre os quais: alcançar a integração financeira mediante a adoção de mecanismos compatíveis com as políticas econômicas e fiscais dos Estados-membros; a integração industrial e produtiva, com especial atenção às pequenas e médias empresas, cooperativas, redes e outras formas de organização produtiva entre outros.

Por sua vez, as Decisóes do Conselho do MERCOSUL - CMC no 24 e no $57^{2}$ de 2012 destacam que os países membros da UNASUL acordaram promover iniciativas de diálogo sobre temas de interesse regional ou internacional e consolidar mecanismos de cooperação com outros grupos regionais, Estados e outras entidades com personalidade jurídica internacional, envolvendo por sua vez, a República Cooperativista da Guiana e a República do Suriname como convidados das reunióes dos órgãos da estrutura organizacional do MERCOSUL, para tratar de interesses comuns.

Tanto o MERCOSUL quanto a UNASUL atuam como atores nesse processo de integraçáo mesmo que tenham objetivos específicos, em parte. No entanto, uma das maiores dificuldades para a integração regional entre os países do MERCOSUL encontra-se na harmonização das legislaçóes dos Estados partes, em especial no Brasil.

O Sistema Tributário Brasileiro é abrangente e com diversas disposiçóes protetivas aos contribuintes em especial ao tratar dos princípios constitucionais aplicados à tributação.

A evolução do processo de integração do MERCOSUL depende da harmonização das legislaçóes aduaneiras dos Estados Partes, conforme consta do art. $1^{\mathrm{o}}$ do Tratado Assunção, bem como da eliminação da incidência cumulativa do imposto sobre a importação e da distribuição da receita aduaneira.

O presente artigo tem como objetivo apresentar consideraçôes sobre o Código Aduaneiro do MERCOSUL - CAM, em especial sobre a exportação, levando em consideração a possibilidade da extensão dos estudos alcançar os demais países que integram a UNASUL. A aprovaçáo do Código Aduaneiro constitui um instrumento de fundamental importância para a concretização da União Aduaneira uma vez que uniformiza as normas e procedimentos aduaneiros dentro do bloco, possibilitando maior segurança jurídica. Dessa forma, poderá ser verificada a importância do CAM para o processo de regionalização

2 Por meio da referida Decisão, o CMC instruiu o GMC - Grupo do Mercado Comum para apresentar proposta para regular o regime de participação de Guiana e Suriname nas reunióes do MERCOSUL, bem como regime de celebração de acordos do bloco com esses países, inclusive a adesão a acordos adotados pelos Estados Partes e Associados do MERCOSUL, considerando ainda o Acordo Quadro de Associação entre o MERCOSUL e a Guiana (Dec. 09/13). 
e integração econômica com os impactos que poderá provocar para o desenvolvimento do MERCOSUL e possivelmente para a UNASUL.

A análise passará pela literatura jurídica brasileira, do MERCOSUL e da UNASUL, utilizando-se o método dedutivo.

\section{O Código Aduaneiro do MERCOSUL: Antecedentes e Vigência}

Com a zona de livre comércio no MERCOSUL o próximo passo para união aduaneira, foi a criação de uma tarifa comum pelos Estados integrantes do Bloco. Daí então a instituição da Tarifa Externa Comum - TEC. Essa tarifa deve ser aplicada pelos Estados partes sobre todas as importaçóes que esses realizarem junto a países externos ao bloco. De igual modo, podem ser consideradas neste contexto as Listas de Exceçóes à TEC. Referidas listas demonstram um dos maiores obstáculos que devem ser superados pelo MERCOSUL para o avanço da integração econômica. As Listas são compostas de produtos referentes a bens de informática, de capital e de telecomunicaçóes bem como de outras exceções nacionais.

O Código Aduaneiro do MERCOSUL - CAM, denominado como Código Marco, ${ }^{3}$ foi aprovado pela Decisão no $27 / 10$ do Conselho do MERCOSUL - CMC. Referido Código tem como antecedente o Tratado de Assunção e o Protocolo de Ouro Preto. A aprovação do CAM já era uma necessidade desde a formação do bloco do Cone Sul. No entanto, para a sua vigência e necessário a aprovação do mesmo, por pelo menos dois Estados do Bloco. A Argentina recepcionou o CAM pela Lei no 26.795 de 21/11/12. As normas do Código Aduaneiro passarão a ser aplicadas pelos países integrantes do MERCOSUL, tão logo, os parlamentos nacionais ratifiquem o novo ordenamento jurídico aduaneiro, que regulará o comércio internacional dos Estados Partes do Bloco. ${ }^{4}$

Inicialmente, por força da Resolução GMC no 13/1994 e do SGT no 02 foi encomendada a elaboração do Projeto do Código Aduaneiro do MERCOSUL, que foi aprovado por meio da Decisão CMC no 25/1994, tendo por escopo harmonizar e uniformizar os métodos e legislaçóes dos quatro países que integram o MERCOSUL. Por força do

3 Na cidade de Buenos Aires na Argentina, nos dias 26 e 27/08/2010, a Universidade Austral e o Instituto Argentino de Estudos Tributários, organizaram o I Congresso Internacional de Direito Aduaneiro do MERCOSUL, coordenado pelo Dr. Alejandro D. Perotti daquela Universidade, com o objetivo de discutir o Projeto do Código Aduaneiro do MERCOSUL. No entanto, em 02/08/2010, o Código Aduaneiro do MERCOSUL - CAM, foi aprovado pela Decisão no 27/10 do Conselho do Mercado Comum. Durante o Evento foi analisado o CAM com a participação de diversos representantes dos países que integram o MERCOSUL bem como convidados de outros países. Referido evento teve um papel preponderante na discussão da temática cujas conclusốes demonstram a preocupação dos conferencistas sobre a interpretação, a vigência e a eficácia do CAM.

4 Em 29/11/2012 o Conselho do MERCOSUL criou o Grupo Ad Hoc de Regulamentação do Código Aduaneiro do MERCOSUL. 
artigo 185 do Código, este somente entraria em vigor, trinta dias depois da ratificação por dois países. Considerando que somente o Paraguai ratificou o Código, o mesmo não teve vigência. ${ }^{5}$ Assim, até agosto de 2010, foram realizadas diversas tentativas para aprovação do Código.

O Código Aduaneiro de $2010^{6}$ possui cento e oitenta e um artigos, dispondo sobre normas aduaneiras fundamentais para o MERCOSUL, como definiçóes básicas, procedimentos de exportação e importaçáo, regimes aduaneiros especiais, áreas com tratamento aduaneiro especial e tributos aduaneiros. Estabelece o âmbito de aplicação e o território aduaneiro que regula o comércio entre os países do bloco mercosulino e entre outros Estados. Os Estados Partes deveriam efetuar as consultas e gestóes necessárias para a eficaz implementação do mesmo dentro de seus respectivos sistemas jurídicos, no período de seis meses.

É importante ressaltar que a Decisão no 27/10 do Conselho Comum do MERCOSUL estabeleceu que os Estados Partes se comprometem a harmonizar aqueles aspectos não contemplados no Código Aduaneiro do MERCOSUL e que tal decisão deverá ser incorporada aos ordenamentos jurídicos dos Estados Partes. ${ }^{7}$ Referida Decisão detalha que as legislaçóes aduaneiras de cada um dos Estados partes serão aplicáveis supletivamente dentro de suas respectivas jurisdiçôes, nos aspectos que não são regulados pelo Código.

Ressalta Vivian Amaral:

A adoção de um Código Aduaneiro Comum traz consigo uma missão: evitar que as divergências alfandegárias de mútua cooperação econômica para a circulação de bens e serviços no MERCOSUL seja regulamentada, além de reconhecer, por parte dos Estados a união aduaneira plena do bloco, tendo em vista que o bloco, nos dias atuais, encontra-se no estágio de uniâo aduaneira imperfeita; possui características desta e de uma zona de livre comércio. ${ }^{8}$

5 Escreve Labrano que as "objeciones a su contenido, fueron la causa de que los demás Estados no lo ratificaran, esencialmente referidas a cuestiones indefinidas respecto a las condiciones para la eliminación del doble cobro de la renta aduanera, así como la necesaria interconexión que requiere la aplicación de un Código Aduanero común”. LABRANO, Roberto Ruiz Díaz. Unión Aduanera em el MERCOSUR Nuevos desafíos para las Administraciones Aduaneras y Operadores ADUA. Revista do Centro de Desp. de Aduana del Paraguay, in www.cdap.org.py/wp-content/uploads/2012/04/16_pdfsam_ revista-julio-20111.pdf, p. 30.

6 O CAM surgiu com base na Decisão CMC no 54, de 2004, Resolução GMC no 40, de 2006 e Decisão CMC no 54, de 2006, sendo que esta constituiu o Grupo Ad Hoc para Redação do Código Aduaneiro do MERCOSUL (GAHCAM).

7 As legislaçóes aduaneiras de cada Estado Parte serão aplicáveis supletivamente dentro de suas respectivas jurisdiçóes, nos aspectos não regulados especificamente por este Código, por suas normas regulamentares e complementares. Manterão sua validade, no que náo contrariem as disposiçóes do Código (CAM), as normas editadas no âmbito do MERCOSUL em matéria aduaneira. Manterão sua validade os tratados internacionais que se encontrem vigentes em cada Estado Parte na data de entrada em vigor do Código.

8 AMARAL, Vivian Henriques de Mello Peixoto. O MERCOSUl e o Código Aduaneiro Comum. Ius

Gentium, Curitiba, ano 4, n. 8, p. 229, jul./dez. 2010. 
É corrente sinalizar que as crises econômicas têm abalado o mundo com reflexos para diversos países, entre eles os países do MERCOSUL. E isto pode afetar posicionamentos que exigem compensaçôes diferentes daquelas que estáo acordadas a partir do Tratado de Assunção. Deve-se ter em conta que as regras estabelecidas não podem ser alteradas a cada crise.

Os regimes de proibiçôes de importação e de exportação também denominados de restriçôes diretas ou restriçóes não tarifárias devem ser considerados junto com os regimes aduaneiros como aspectos de vital importância na legislaçáo aduaneira. É importante ressaltar que a questáo relativa às restriçóes diretas de mercadorias refere-se a um tema relevante que não só tem sido regulado nos Códigos Aduaneiros dos Estados e também nos Tratados Internacionais, como é o caso do GATT (Acordo Geral sobre Tarifas Aduaneiras e Comércio).

Também em 02.08.2010 o Conselho do Mercado Comum aprovou a Decisão no 10/10 que dispóe sobre eliminação da dupla cobrança da TEC - Tarifa Externa Comum e da Distribuição da Renda Aduaneira. De igual modo, tal decisão necessita ser incorporada no ordenamento jurídico dos Estados Partes do Bloco.

O Código Aduaneiro do MERCOSUL é o principal instrumento de regulação das relaçôes do bloco com terceiros países, e a legislação complementar dos tributos sobre o comércio exterior devem atuar no sentido de corrigir as desigualdades regionais sociais e econômicas, promovendo a igualdade com a harmonização ou a uniformização de legislação e os procedimentos aduaneiros. Não consiste apenas em ter uma tarifa para as importaçôes de fora da região e também eliminar as múltiplas incidências diretas e indiretas de tributos sobre as rendas. Os produtos externos aos países do MERCOSUL, quando importados, estâo sujeitos ao pagamento do imposto de importação nos termos da legislação do país de entrada.

O MERCOSUL, com o Código Aduaneiro, segue com "mais músculos em busca da consolidação da união aduaneira, que, é bom que se diga, já é uma ambiciosa modalidade de acordo comercial, pois exige de seus membros não só o compromisso de abolir todas as barreiras internas ao comércio, mas a de adoptar uma pauta aduaneira comum em relação a Estados terceiros, para além de uma política comercial comum, passos que só se alcançam após muitos anos de árduos esforços e muita vontade política”.

$\mathrm{O}$ artigo $5^{\circ}$ do Tratado de Assunção previu abertura comercial entre os países do MERCOSUL a partir de 31 de dezembro de 1994. Assim, a alíquota do imposto sobre a importação em todas as operaçôes no Bloco mercosulino seria zero. Esse prazo foi prorrogado,

9 ACCIOLY, Elizabeth. Duas Décadas de MERCOSUL: Valeu a pena? In Revista Argumentum UNIMAR, n. 12, 2011, p. 32 . 
de forma que o regime de adequação, com alíquotas de importação no Bloco teve vigência para o Brasil até 1998 e para os demais países até 1999.

Mesmo com o término do regime de adequação, ainda há produtos sobre os quais incide imposto sobre a importação nas operações intrabloco. Atualmente são bens do setor automotivo e açúcar. Em relação aos demais, a alíquota é zero nas operações entre os países do MERCOSUL, desde que sejam cumpridas as regras de origem. ${ }^{10}$ É importante destacar que é necessária a revogação a incidência do imposto sobre a importação intrabloco de açúcar e de bens do setor automotivo.

Para eliminar a dupla tributação do imposto sobre a importação (TEC) nas operaçôes intrabloco, está a distribuição de receita aduaneira. No entanto, é necessário consignar que a Decisão CMC no 10/2010, estabeleceu um cronograma para efetuar de modo gradativo os processos pertinentes. Estão previstas três etapas, que devem culminar para a eliminação da dupla cobrança da TEC e a consolidaçáo das regras de distribuição da renda e a livre circulação de mercadorias até o início de 2019. O programa compreende, na primeira etapa (a partir de $1^{\circ}$ de janeiro de 2012), exclusivamente os bens sem transformação; na fase seguinte (a partir de $1^{\circ}$ de janeiro de 2014), os bens gravados com alíquotas de importação de $2 \%$ e 4\%; e a na terceira etapa (a ser definida entre 2016 e 2019), os demais bens gravados com alíquotas superiores a $4 \%$.

Para a implementação dessas três etapas será necessário o atendimento das seguintes situaçóes, nos termos da Decisão CMC no 10/2010: a) a interconexão em linha dos sistemas informáticos de gestão aduaneira e a base de dados que permita o intercâmbio de informaçóes no que diz respeito ao cumprimento da Política Tarifária Comum - PTC; b) a entrada em vigência do Código Aduaneiro do MERCOSUL; c) o estabelecimento de uma compensação para o Paraguai, considerando sua condição especial e específica como país sem litoral marítimo, sua alta dependência das arrecadaçóes aduaneiras e a eventual perda de arrecadação decorrente da eliminação da dupla cobrança da TEC; d) o monitoramento periódico dos impactos econômicos e comerciais resultantes da eliminação da dupla cobrança da TEC sobre os Estados Partes. Em função das informaçóes que resultarem do monitoramento, o GMC poderá introduzir ajustes no mecanismo de distribuição e propor medidas para mitigar possíveis efeitos negativos da implementação da Decisão $\mathrm{CMC}$ n$^{\circ}$ 54/04.

\section{A Questão da Exportação no Código Aduaneiro - CAM}

A implantação e a manutenção de um Bloco de comércio é uma tarefa das mais árduas a serem enfrentadas por governos de diversos países por todo o mundo. No caso

10 MEIRA, Liziane Angelotti. Integração Regional e Tributos sobre o comércio exterior no MERCOSUL, in Revista da PGFN, Ano 1, n. 2, 2011, p. 67. 
do Brasil e sua atuação no MERCOSUL dentre os muitos desafios que devem ser enfrentados, talvez o maior deles, seja o de harmonizar as legislaçóes pertinentes.

Desta forma, quando entra em vigor uma resolução política, como é no caso o CAM, relacionado a participação num bloco comercial, normalmente isto significa uma vitória para a diplomacia da reciprocidade. Mas, também pode representar problemas de interpretação, de adaptação, de harmonização e questóes que podem comprometer a integração econômica do MERCOSUL. Neste caso os interesses de determinados Estados Partes podem conflitar com objetivos maiores como a integração entre os países que compóem o Bloco mercosulino. ${ }^{11}$

O processo de integração aduaneira requer a efetiva realização de três bases formadoras: a livre circulação de mercadorias que ocorre com a plena união aduaneira; a legislação aduaneira, essencial e de natureza econômica, normatizando e regulamentando aspectos concernentes para importação e para exportação das mercadorias; a Tarifa Externa Comum - TEC e a lista de mercadorias codificadas segundo a Nomenclatura Comum do MERCOSUL aplicáveis às mercadorias oriundas de terceiros países.

A adoção da TEC estabelece uma base tarifária que rege a incidência tributária. Excluídos da TEC estão os produtos negociados pelos Estados- Partes com os países da ALADI - Associação Latino-americana de Integração e também, Produtos do Regime de Adequação Final aos quais se aplica uma tarifa decrescente.

O caráter reservado da maioria dos documentos relativos à elaboração do CAM, não permite inferir quais foram avanços efetivos promovidos desde meados de 2006, quando o Grupo do MERCOSUL aprovou a Resolução 40/2006. Vale lembrar, que na ocasião, foram definidas importantes diretrizes a ser seguidas na elaboração do CAM. Dentre elas, destacaram-se ${ }^{12}$ : Fato Gerador da Obrigação Tributária, Alcance do Código Aduaneiro, Âmbito de Aplicação Espacial do CAM, Território Aduaneiro, Infraçóes Aduaneiras entre outras, Mar Territorial e Depósitos Aduaneiros.

Após a aprovação da Resolução no 40/06 do MERCOSUL, os negociadores nacionais afirmaram com otimismo que mais de $80 \%$ do CAM já havia sido acordado. No entanto, dois anos mais tarde, em Tucumán os negociadores também afirmaram que ainda tinham alguns obstáculos que deveriam ser superados, pelo menos em três áreas: a)

11 No processo de integração do MERCOSUL podem ocorrer dificuldades de ajustes ou acordos que envolvam as questóes de importação e de exportação, sendo as mais comuns aquelas que envolvem as duas maiores economias do bloco, ou seja, do Brasil e da Argentina. Exemplos destas relaçốes são muitos, como as queixas contra as práticas comerciais provenientes de acordos do Bloco, feitas por produtores de arroz e trigo na região Sul do Brasil ou as barreiras impostas pela Argentina a importação de produtos de "linha branca” brasileiros como fogóes geladeiras e máquinas de lavar entre outros.

12 Informe MERCOSUL no $14-2^{\circ}$ sem./2008 e $1^{\circ}$ sem./2009, CNI, pág. 78/9. 
a delimitação precisa do território aduaneiro do MERCOSUL; b) a definição das áreas aduaneiras especiais, inclusive o mar territorial e c) o tema dos direitos de exportação. ${ }^{13}$

Referente ao tema dos direitos de exportação, segundo o representante da Argentina, a redação do CAM contemplava três alternativas: a) não incluir os direitos de exportação no Código; b) determinar que esses direitos fossem definidos em nível comunitário ou c) permitir que cada país estabelecesse seus direitos de exportação. Ele também declarou que seu País defendia a última alternativa. Do outro lado, o Uruguai manifestou sua preferência no sentido de que os direitos de exportação ficassem sujeitos à aprovação do Conselho do Mercado Comum. ${ }^{14}$

A Decisão no 27/10 do Conselho do MERCOSUL que aprovou o CAM, destaca no artigo $1^{\circ}-4$, que as legislaçóes aduaneiras de cada Estado Parte serão aplicáveis supletivamente dentre de suas respectivas jurisdiçóes nos aspectos não regulados especificamente pelo Código, por suas normas regulamentares e complementares. Notadamente tais regulamentos terão como objetivos facilitar a aplicação no âmbito interno de cada país, considerando suas legislaçóes específicas, após a recepção do CAM. Trabalho este, de representativa importância para a eficácia do Código. ${ }^{15}$

De igual modo, o Artigo $3^{\circ}$ destaca como definição básica: Exportação - a saída de mercadoria do território aduaneiro do MERCOSUL. Já o Artigo $7^{\circ}$ ressalta que a Administração Aduaneira é o órgão nacional competente, conforme as normas vigentes em cada Estado Parte, para aplicar a legislação aduaneira, prescrevendo as seguintes situaçóes: a) aplicar as normas emanadas dos órgãos competentes, em matéria de proibiçôes ou restriçôes à importação e à exportação de mercadorias; e, d) determinar, arrecadar e fiscalizar os tributos aduaneiros e os que lhe forem demandados.

O CAM dispóe sobre os tributos aduaneiros no Título XI, artigos 157 a 171. Os tributos regulados pelo Código são: o imposto sobre a importação e as taxas em razão de serviços prestados no curso do processo de importação ou exportação. O artigo 157-2

13 Ibidem.

14 Informe MERCOSUL no 14 - 20 sem./2008 e 1º sem./2009, CNI, pág. 79.

15 Nos últimos anos, a cobrança de tributos aduaneiros na Argentina, especialmente do imposto sobre a exportação, além de revelar importância no orçamento (mais de um quinto das receitas) também foi adotada como política nacional para reduzir a inflação. Por outro lado, o Uruguai está ressentido dos efeitos dessa postura, em razão de sua dependência de produtos importados argentinos. Sendo assim, não foi possível prever no CAM um regime comum para o imposto sobre a exportação e nem regras gerais para que os Estados Partes o regulassem Nesse contexto, diante da falta de perspectiva de solucionar essa questão em curto ou médio prazo, optou-se por, nessa matéria, fazer constar apenas a disposição abaixo no item 4 do art. 157: "O presente Código Aduaneiro não trata sobre imposto de exportaçáo e, por essa razão, a legislação dos Estados Partes será aplicável no seu território aduaneiro preexistente à sanção deste Código, respeitando os direitos dos Estados Partes.” Cf. MEIRA, Liziane Angelotti. Integração Regional e Tributos sobre o Comércio Exterior no MERCOSUL, in Revista da PGFN, Ano 1, n. 2, 2011, p. 68. 
menciona sobre as multas decorrentes do não pagamento de tributos. ${ }^{16} \mathrm{E}$ ainda, o artigo 157 estabelece no item 4, que o referido Código Aduaneiro não trata sobre imposto de exportação e, por essa razão, a legislação dos Estados Partes será aplicável no seu território aduaneiro preexistente à sanção do Código, respeitando os direitos dos Estados Partes. Alejandro Perotti, ressalta que o item 4 do artigo mencionado "no trata sobre derechos de exportación y, por lo tanto, la legislación de los Estados Partes será aplicable en su territorio aduanero preexistente a la sanción de este Código, respetando los derechos de los Estados Partes" ${ }^{17}$ Afirma também que, "los únicos derechos de exportación que el código puede regular (aún cuando sea para decir que 'no (los) trata') son aquellos que se aplican en relación al territorio aduanero, es decir aquellos que repercuten sobre bienes que se extraen del territorio aduaneiro". ${ }^{18}$

O que deve ser destacado é o que o Código e suas Normas de Aplicação (art. 1º) constituem a legislação aduaneira aplicável a totalidade do território aduaneiro do MERCOSUL, e aos enclaves ${ }^{19}$ concedidos ao seu favor, e regulará o comércio internacional dos Estados Partes do MERCOSUL com terceiros países ou blocos de países. A legislação aduaneira do MERCOSUL não será aplicada aos exclaves ${ }^{20}$ concedidos em favor de terceiros países ou blocos de países.

Pelo teor do artigo $2^{\circ}$ do CAM, o Território Aduaneiro é aquele no qual se aplica a legislação aduaneira comum do MERCOSUL. E o artigo $3^{\circ}$ estabelece diversas definições básicas, destacando-se: Exportação: a saída de mercadoria do território aduaneiro do MERCOSUL. Daí, a afirmativa de Perotti:

Así, el territorio aduanero del Mercosur es la sumatoria del territorio aduanero de los Estados, por lo cual los derechos de exportación a los que hace referencia el código son los que inciden sobre los bienes que se exportan hacia afuera del bloque. Por si existiera alguna duda, la exportación es definida en el código como "la salida de mercadería del territorio aduanero del Mercosur" (artículo 3), por lo que los "derechos" deben repercutir sobre lo que "sale" del Mercosur. ${ }^{21}$

16 Esse tema não foi tratado com maior abrangência conforme determinações constantes do Anexo da Resoluçáo GMC 40, de 2006, que designou o Grupo Ad Hoc para Redação do Código Aduaneiro do MERCOSUL. Este Grupo não recebeu poderes para incluir no projeto as seguintes matérias: infraçóes aduaneiras e sançóes pecuniárias; disciplinamento da profissăo de despachante aduaneiro; decadência e prescriçáo dos tributos aduaneiros.

17 PEROTTI, Alejandro D. Mercosur: Código Aduanero y derechos de exportación publicado em 18.10.2010 in http://regionnortegrande.com.ar/?articulo=2145

18 Ibidem.

19 Enclave: a parte do território de um Estado não integrante do MERCOSUL na qual se permite a aplicação da legislação aduaneira do MERCOSUL, termos do acordo internacional que assim o estabeleça (art. $3^{\circ}$ ).

20 Exclave: a parte do território de um Estado Parte do MERCOSUL na qual se permite a aplicação da legislação aduaneira de um terceiro Estado, nos termos do acordo internacional que assim o estabeleça (art. $3^{\circ}$ ).

21 PEROTTI, Alejandro D. Mercosur: Código Aduanero y derechos de exportación publicado em 18.10.2010 in http://regionnortegrande.com.ar/?articulo=2145 
Até o dia anterior à aprovação havia no Projeto regras sobre esse imposto. No entanto, esclarece que devido a impasses entre Argentina e Uruguai, decidiu-se excluir essa matéria do Código. Assim, o CAM se tornou incompleto, mas se tornou possível, em termos de aprovação e incorporação. Acrescenta que nos últimos anos, a cobrança de tributos aduaneiros na Argentina, especialmente do imposto sobre a exportação, além de revelar importância no orçamento (mais de um quinto das receitas) também foi adotada como política nacional para reduzir a inflação. ${ }^{22}$

Outro ponto que precisa ser observado com atenção refere-se ao disposto no artigo 178-1(a) do Código que estatui que durante o processo de transição até a conformaçáo definitiva da União Aduaneira, o ingresso ou a saída de mercadorias de um Estado Parte, para outro serão considerados como importação ou exportação entre distintos territórios aduaneiros. Assim, até a conformação definitiva (2019) conforme dispóe a Decisão 10/2010, as vendas de um Estado parte para outro Estado Parte do Bloco, seráo exportaçóes desde distintos territórios aduaneiros, e neste sentido "recobra vigencia "intrazona" la posibilidad prevista en el artículo 154-7 del código, esto es la aplicación de derechos de exportación". ${ }^{23}$

Daí questionar: Como o Código Aduaneiro do MERCOSUL não dispõe sobre a incidência de imposto de exportação, é possível aos Estados Partes aplicarem os direitos de exportação intrazona? Se o CAM não proíbe expressamente, é possível os Estados recorrerem para a incidência do tributo? O Código Aduaneiro prevê expressamente que não se aplica às operações de exportação (art. 157-4), e, sim somente para a importação, destacando que normas regulamentares, em momento oportuno, tratarão da questão. Há

22 MEIRA, Liziane Angelotti. Integraçấo Regional e Tributos sobre o comércio exterior no MERCOSUL, in Revista da PGFN, ano 1, n. 2, 2011, p. 68. Por outro lado, o Uruguai está ressentido dos efeitos dessa postura, em razão de sua dependência de produtos importados argentinos. Sendo assim, não foi possível prever no CAM um regime comum para o imposto sobre a exportaçáo e nem regras gerais para que os Estados Partes o regulassem Nesse contexto, diante da falta de perspectiva de solucionar essa questáo em curto ou médio prazo, optou-se por, nessa matéria, fazer constar apenas a disposição abaixo no item 4 do art. 157: "O presente Código Aduaneiro não trata sobre imposto de exportação e, por essa razão, a legislaçấo dos Estados Partes será aplicável no seu território aduaneiro preexistente à sançấo deste Código, respeitando os direitos dos Estados Partes", acrescentou Liziane.

23 PEROTTI, Alejandro D. Mercosur: Código Aduanero y derechos de exportación publicado em 18.10.2010 in http://regionnortegrande.com.ar/?articulo=2145. Acrescenta Perotti, que "ni aún en este caso esta posibilidad es válida, dado que el CAM es una "Decisión" del CMC, que por su jerarquía inferior no puede modificar el Tratado de Asunción, que específicamente prohibe los derechos de exportación intrazona. La relación entre una Decisión del CMC y el Tratado de Asunción puede equipararse a la que se da entre una ley del Congreso y la Constitución; así como una ley no puede reformar la Constitución, una Decisión del CMC no puede hacer lo propio con el Tratado de Asunción. Finalmente, a pesar de la trascendencia que ha tenido la aprobación del CAM, éste en nada ha innovado el estado de situación preexistente en torno a la prohibición absoluta de derechos de exportación intrazona, contenida en el Tratado de Asunción, con lo cual toda empresa que exporte al Mercosur tiene la posibilidad de reclamar la devolución de lo que haya abonado". 
com isso, certa inquietude uma vez que a interpretação dos artigos do CAM pode gerar outros desdobramentos que terão seus reflexos no desenvolvimento dos países do Bloco e consequentemente dificultará o seu processo de integração. Para esta questão podemos nos valer do artigo $1^{\circ}$ do Tratado de Assunção que reza que os Estados Partes assumem, naquele ato, o compromisso de harmonizar suas legislaçóes para o fortalecimento do processo de integração. Implica assim na livre circulação de bens, serviços e fatores de produção entre os países, entre eles a eliminação dos direitos alfandegários e restrições não tarifárias à circulação de mercadores e de qualquer outra medida de efeito equivalente, entre outros o estabelecimento de uma tarifa externa comum. No Anexo I, artigo 2o, inciso b do Anexo I do Tratado de Assunção, vem demonstrado que se entenderá por restriçóes, qualquer medida de caráter administrativo, financeiro, cambiário ou de qualquer natureza, mediante a qual um Estado Parte, impeça ou dificulte por decisão unilateral o comércio recíproco.

Além das Definiçôes Básicas, mencionadas anteriormente, o CAM dispóe sobre a definição de mercadoria que corresponde a todos os bens suscetíveis de importação ou de exportação, ou seja, todo bem suscetível de um destino aduaneiro. Essa definição é corrente e aceita no direito do comércio internacional. Meira destaca que na legislação brasileira, não há uma definição de mercadoria para efeito de comércio internacional, o que tem gerado sérios problemas de interpretação. ${ }^{24}$

Devem ser verificados também os destinos aduaneiros de exportação e os regimes aduaneiros de exportação. O destino aduaneiro de exportação é o tratamento previsto para a mercadoria que sair do território aduaneiro, que deve ser sempre sua inclusão em um regime aduaneiro de exportação, nos termos do artigo 78-1, do CAM. Os regimes aduaneiros de exportação, por sua vez, são: exportação definitiva, exportação temporária para reimportação no mesmo estado, exportação temporária para aperfeiçoamento passivo e trânsito aduaneiro.

\section{Tributação sobre o Comércio Exterior: Imposto sobre a Exportação no Brasil}

Os principais tributos que incidem sobre as operaçóes de comércio exterior previstos na Constituição da República Federativa do Brasil são: Imposto sobre a Exportação, para o exterior, de produtos nacionais ou nacionalizados, Imposto de Importação de produtos

24 No entanto, o intérprete brasileiro tem transportado, sem o devido cuidado, o conceito de mercadorias para efeitos de cobrança do ICMS sobre as operaçóes internas para interpretar a legislação sobre tributação pelos Estados Federados na importação (art. 79 CAM). MEIRA, Liziane Angelotti. Reflexóes sobre o Código Aduaneiro do MERCOSUL. In Revista de Direito Internacional Econômico e Tributário RDIET, Brasília, V. 6, no 2, p. 259-290, Jul-Dez, 2011, p. 266. 
estrangeiros, ICMS (Imposto sobre a Circulação de Mercadorias e Serviços), IPI (Imposto sobre Produtos Industrializados) e COFINS/PIS (Contribuição para o Financiamento da Seguridade Social/Programa de Integração Social). No entanto, algumas situaçôes que envolvem a exportação de produtos estão imunes ou isentas de alguns dos tributos mencionados, conforme prevê a Constituição Federal e a legislação complementar específica. O Decreto 6759/09 regulamenta a administração das atividades aduaneiras, a fiscalização, o controle e a tributação das operaçóes de comércio exterior, incluindo os impostos acima mencionados.

Segundo a Constituição Federal (art. 153, II), o Imposto de Exportação é de competência exclusiva da União e tem como fato gerador a saída de produto nacional ou nacionalizado do território nacional. A exportação significa, portanto, a saída a título definitivo da mercadoria do país.

Este imposto tem função fiscal e regulatória controlando a saída de produtos do país, atendendo assim, também a função extrafiscal do tributo. Não está sujeito ao princípio da anterioridade, podendo ser alterado no mesmo exercício financeiro, pelo Poder Executivo que pode a qualquer tempo, alterar (reduzir ou aumentar) suas alíquotas. Atendidas as condiçôes e os limites previstos em lei (art. $153 \int 1^{\circ} \mathrm{e}$ art. 150, S $1^{\circ} \mathrm{da}$ Constituiçâo Federal), a fim de ajustá-los aos objetivos da política cambial e do comércio exterior, as alíquotas podem ser alteradas, como já exposto anteriormente. Em caso de aumento, a alíquota do imposto náo poderá ser superior a 150\%. Essas alteraçóes podem surtir efeitos a partir da data da publicaçáo no Diário Oficial da União (DOU). Atualmente, poucos produtos têm incidência do Imposto de exportaçáo, sendo que a grande maioria é tributada com alíquota zero, devido à política governamental de incentivo às exportaçóes. ${ }^{25}$

O Imposto sobre Exportação está regulado no Código Tributário Nacional nos artigos de 23 a 28, que fixa as alíquotas, a base de cálculo, contribuintes e o fato gerador. Referida regulamentação está também no Decreto-Lei no $1.578 / 77$ com as devidas atualizações.

O fato gerador se caracteriza com a saída de produto nacional, ou nacionalizado, para outro país, quando da expedição da Guia de Exportação ou documento equivalente, qualquer que seja a finalidade de quem remete. Com exceção dos casos pessoais, como bagagens, estabelecidos no art. 23 do CTN e no art. $1^{\circ}$ do Decreto-Lei no $1.578 / 77$, não importa que se trate de doação ou mercadoria do próprio remetente, o fato da saída para fora do país ocasiona o fato gerador.

25 Os produtos sujeitos ao imposto sobre a exportação estão descritos no Anexo N da Portaria SECEX no 25/08. Destacam-se entre os produtos sujeitos à incidência do Imposto de Exportação: Peles e couros de animais - 9\%; armas e muniçóes - 150\%, fumo, cigarro, filtro e papel para cigarros - 150\%, couros e peles curtidos de bovinos depilados mas náo preparados de outra forma $-9 \%$. 
Contribuinte do imposto é o exportador que deve recolher o tributo ou quem a lei a ele equiparar, considerada qualquer pessoa que promova a saída de produtos do território nacional, podendo também a lei equiparar terceiro ao exportador. $\mathrm{O}$ exportador deve recolher o tributo antes de efetivada a saída definitiva da mercadoria para o exterior.

O Poder Executivo indica quais são os produtos que estão sujeitos à incidência do imposto sobre a exportação, que tem como base de cálculo do imposto o preço normal que o produto, ou seu similar, alcançaria, ao tempo da exportação, em uma venda em condiçôes de livre concorrência no mercado internacional, não podendo ser inferior ao seu custo de aquisição ou de produção, acrescido dos tributos incidentes e da margem de lucro mínima de $15 \%$ sobre a soma dos custos, impostos e contribuiçôes, observadas as normas expedidas pelo Poder Executivo, mediante ato do Conselho Monetário Nacional. As saídas de produtos que tenham ingressado em regime de admissão temporária ou de produtos que devam retornar ao país não configuram propriamente uma exportação. ${ }^{26}$

A lei pode adotar como base de cálculo a parcela do valor ou do preço excedente de valor básico, fixado de acordo com os critérios e dentro dos limites por ela estabelecidos. A exportação pode ser realizada de forma direta e indireta dependendo da forma de realização da operação. Em razão da política de incentivo fiscal concedida pelo governo brasileiro, as exportaçóes gozam de diversos benefícios tributários. Na exportação direta, o próprio produtor ou revendedor envia a mercadoria para o destinatário (importador) situado fora do Brasil, sem utilizar intermediários. Já na exportaçáo indireta, que ocorre com a remessa com a finalidade específica de exportação, o produtor remete o produto a uma empresa comercial exportadora, com a finalidade específica de exportação, com benefícios e incentivos fiscais, conforme prevê a legislação aplicável.

Atualmente todas as saídas de mercadorias, produtos ou bens com destino ao exterior gozarão de benefícios fiscais relativos ao ICMS, $\mathrm{IPI}^{27} \mathrm{em}$ forma de imunidades previstas na Constituição Federal e as isençóes previstas em leis e regulamentos referentes ao PIS/PASEP e COFINS, que diferenciam se é cumulativo ou não cumulativo, bem como diferencia a exportação direta e indireta quanto à incidência dos referidos tributos.

No entanto, não há benefício fiscal aplicável a apuração do IRPJ - Imposto de Renda da Pessoa Jurídica ou da CSLL - Contribuição Social sobre o Lucro Líquido. ${ }^{28}$ Assim, o lucro, renda ou proventos provenientes das operações de exportação será tributável pelos

$26 \mathrm{O}$ preço à vista do produto, $\mathrm{FOB}$ ou posto na fronteira, é indicativo do preço normal. Quando o preço do produto for de difícil apuração ou for susceptível de oscilações bruscas no mercado internacional, o Poder Executivo, mediante ato do Conselho Monetário Nacional, fixará critérios específicos ou estabelecerá pauta de valor mínimo, para apuração de base de cálculo.

27 IPI - Imposto sobre produtos industrializados (Constituição Federal art. 153, $₫ 3^{\circ}$, III); ICMS Imposto sobre a circulaçáo de mercadorias e serviços (Constituição Federal art. 155, $\$ 2^{\circ}$, X, alínea a);

28 Instituída pela Lei no $7.689 / 88$. 
tributos acima mencionados, quer sejam: IRPJ e CSLL, conforme dispuser a legislação federal quando da ocorrência do fato gerador, ou seja, da saída do produto do território nacional.

Todos os benefícios fiscais mencionados, aplicáveis à exportação direta e à indireta são condicionados à efetiva remessa da mercadoria para o exterior.

Há que ser considerado para fins de análise da exportação o drawback interno (verde -amarelo). Trata-se de operação realizada no Brasil, entre fornecedor nacional de insumos para uma indústria exportadora, que industrializará tais insumos e realizará a posterior exportação do produto resultante. Com isso ocorrerá a modalidade suspensão dos tributos federais incidentes na venda entre fornecedor e indústria exportadora (IPI, PIS/PASEP, COFINS). No entanto, ocorrerá a tributação do ICMS, podendo ocorrer alguma isençáo do imposto se a legislação estadual possibilitar tal benefício.

\section{Do Tratado de Assunção à UNASUL e as Repercussões do CAM}

As restriçóes correspondem quaisquer medidas de caráter administrativo. O Programa de Liberação Comercial do MERCOSUL estabelece que os países do Bloco se comprometem a eliminar todos os gravames e restriçóes do comércio recíproco. Por gravame se entende os direitos aduaneiros, e, quaisquer outras medidas equivalentes, seja de caráter fiscal, cambial, monetária ou de qualquer natureza que incidam sobre o comércio exterior, conforme estabelece o Tratado de Assunção.

As restriçôes diretas aplicadas às importaçôes, via de regra, são quantitativas e de mecanismos de preços. Já as restriçôes indiretas relacionadas às exportações correspondem às proibiçóes e quotas derivadas da participação do governo na fabricação, venda e comércio de determinados produtos; as restriçóes derivadas de medidas governamentais de incentivo ao desenvolvimento regional e setorial, vantagens fiscais e subvençóes; as restriçóes aos meios de informação e comercialização interna; as restriçôes creditícias do setor importador bem como os impostos internos discriminatórios. ${ }^{29}$ Essas restriçôes muitas vezes não são fáceis de identificação, o que pode impedir a livre circulação de produtos intrazona. A harmonização ou a uniformização regulamentar é o procedimento eficaz para diminuir tais entraves ou barreiras.

Com o Tratado de Assunção, os Estados partes assumiram o compromisso de harmonizar suas legislaçóes, nas áreas pertinentes, para o fortalecimento do processo de integração. Restou claro aos Estados que se tratava de um processo para implantar o Mercado

29 De igual modo destacam-se as restriçôes fitossanitárias: Qualidades de produtos e questôes relacionadas ao meio ambiente; procedimentos arbitrários na classificação aduaneira e programas de investigação e desenvolvimento financiado pelo governo. 
Comum. $\mathrm{O}$ artigo $1^{\circ}$ do referido Tratado destaca que para construção desse mercado comum, implicaria a livre circulação de bens, serviços e fatores de produção entre os países, entre eles a eliminação dos direitos alfandegários e restrições não tarifarias a circulação de mercadorias e de qualquer outra medida de efeito equivalente e estabelecimento de uma Tarifa Externa Comum - TEC. Para a união aduaneira o regulamento deve ser unificado, havendo um conjunto de normas aduaneiras obedecidas por todos os Estados Partes.

Em se tratando do Código Aduaneiro do MERCOSUL, os países poderão apresentar consultas para as regulamentaçóes e para a viabilidade do CAM, mas fundamentalmente, espera-se que o Código seja recepcionado pelos Estados Partes, e, que seja efetivamente aplicado.

O Artigo 135 do Código Aduaneiro estabelece nos itens 1 e 2 que serão consideradas proibiçôes ou restriçóes as medidas que proíbem ou restringem de forma permanente ou transitória a introdução ou retirada de determinadas mercadorias no/ou do território aduaneiro. As proibiçóes ou restriçóes serão de caráter econômico ou náo econômico, de acordo com sua finalidade preponderante.

Já o artigo 136, por sua vez ressalta que as proibiçóes ou restriçóes de caráter econômico somente são aplicáveis aos regimes aduaneiros de importação definitiva e exportação definitiva. E ainda completa que as proibiçóes ou restriçóes de caráter econômico à importaçáo definitiva não afetam a mercadoria que tenha sido previamente exportada temporariamente. As proibiçóes ou restrições de caráter econômico à exportação definitiva não afetam a mercadoria que tenha sido previamente importada temporariamente.

A mercadoria introduzida no território aduaneiro que não possa ser incluída em um regime aduaneiro, em virtude de proibiçôes ou restriçóes, deverá ser retornada ao exterior, reexportada, destruída ou submetida à aplicação de medidas de outra natureza previstas nas normas regulamentares, complementares e nas emanadas dos órgãos competentes é o que preceitua o art. 137 do CAM.

Merecem destaques as prescriçóes do artigo 139 do CAM que estabelece que quando a mercadoria submetida a uma proibição ou restrição de caráter não econômico se encontre em depósito temporário de importação, ou for submetida ou se pretender submetê-la a um regime de importação, a Administração Aduaneira, exigirá que o interessado a retorne ao exterior ou a reexporte dentro do prazo estabelecido nas normas regulamentares.

No âmbito do MERCOSUL, os acordos de restrição de exportações surgiram como uma alternativa, diante das dificuldades políticas e jurídicas para a definição de salvaguardas. Por ora, concentra-se na viabilidade jurídica dessa opção, primeiramente à luz das regras do sistema multilateral e, em seguida, do regional.

$\mathrm{Na}$ UNASUL, por sua vez, quando se trata industrialização na região com muitos recursos naturais, minerais e energéticos, da América do Sul, serão necessárias muitas 
tratativas para efetivar sua realização. Para tanto, devem ser consideradas as questôes tributárias aduaneiras (importação e exportação) que porventura possam incidir no setor hidrelétrico e a mineração, por exemplo, no setor de transportes e as logísticas que envolvem estes segmentos. ${ }^{30}$

O Brasil representa importante papel tanto no MERCOSUL quanto na UNASUL. Embora existam inúmeros problemas, os dois processos integracionistas podem se complementar a fim de contribuir para o desenvolvimento e para a diminuição das desigualdades regionais e a incidência de tributos podem contribuir para a reflexão de sua função social.

José Soares Filho destaca que será efetivada a integraçáo do MERCOSUL, com previsíveis avanços e recuos em sua trajetória. Trata-se de um objetivo condizente com as aspiraçôes de desenvolvimento sócio econômico dos povos da América Latina, cuja realização representará um marco nesse processo. Não obsta ao desenvolvimento deste a UNASUL que está em fase de implantação, que congrega os países da América Latina com o mesmo propósito de integração que o MERCOSUL. Isso porque um processo não exclui o outro, mas ambos se completam, concorrendo para a mais ampla integraçáo latino-americana. ${ }^{31}$

Acredita-se que essa afirmativa seja verdade até certo ponto. Isto porque o MERCOSUL deve ser efetivado como organismo internacional por ainda muito tempo, principalmente para os fins por ele designados. Contudo, auferida a sua missão (pode demorar muitos anos), há de se pensar em fixar a UNASUL como a entidade a comandar os interesses da região. ${ }^{32}$

É pontual a afirmativa de Felix Peña ${ }^{33}$ :

30 Um tributo sobre combustíveis automotivos, vinculado ao financiamento dos transportes foi a receita de sucesso para que o Brasil, um país continental, construísse no passado uma razoável infraestrutura de transportes - sintomaticamente degradada a partir dos anos 80 , quando o tributo foi incorporado à caixa única do Tesouro. A proposta de tributo vinculado esbarra, na América do Sul, numa estrutura tributária que, fora a Argentina e o Brasil, se destacam pela aberraçáo. Enquanto Argentina e Brasil têm cargas tributárias da ordem de $32 \%$ do PIB, nos demais países essa relação oscila em torno dos $16 \%$, variando entre $10 \%$ e $22 \%$. Isso reflete a resistência dos ricos e afluentes a pagar tributos na regiáo. Contudo, se essa tendência náo for corrigida, a maioria dos países da América do Sul năo terá efetivas condiçóes de participar de um projeto comum de desenvolvimento através da integraçáo da infraestrutura, escreveu J. Carlos de Assis, MERCOSUL ataca pelas duas pontas, em 14 de maio de 2015, in http://www. ecofinancas.com/noticias/unasul-ataca-duas-pontas

31 SOARES FILHO, José. MERCOSUL: surgimento, estrutura, direitos sociais, relaçáo com a UNASUL, perspectivas de sua evolução. Revista CEJ, Brasília, Ano XIII, n. 46, p. 36, jul./set. 2009.

32 RABELO, Felipe Cesar José Matos. A Coexistência MERCOSUL-UNASUL, in Revista SJRJ, Rio de Janeiro, v. 18, n. 30, p. 66, abr. 2011. O autor visualiza que a UNASUL deverá ser, no futuro, o organismo estável e representativo e o MERCOSUL, o projeto com prazo de validade. Uma vez alcançada sua meta de caráter representativamente econômico, as bases para a UNASUL estaráo firmadas definitivamente para seguir seus propósitos que são bem mais amplos.

33 PEÑA, Félix. A integração no espaço sul-americano: A UNASUL e o MERCOSUL podem se complementar? In Revista Nueva Sociedad. Diciembre de 2008. In http://www.nuso.org 
Cabe lembrar que a América do Sul se transformou em um espaço geográfico de densidade crescente, diferenças marcantes e grande dinamismo. É, nesse sentido, um verdadeiro mosaico. Tudo indica que continuará sendo assim no futuro. Captar bem as forças profundas desatadas na regiáo é um desafio complexo para quem quer que opere nela, tanto no plano político como, sobretudo, no empresarial.

A interdependência entre os diversos países cresceu substancialmente nas últimas décadas, deixando os sistemas políticos e econômicos nacionais mais próximos e sensíveis ao que ocorre com os países vizinhos. Isso ocorre no plano da produçáo e do comércio, envolvendo empresas transnacionais e, crescentemente também por um número significativo de pequenas e médias empresas originadas na própria região que cresceram gradualmente, e com mais intensidade nos últimos anos. Isto se reflete no intercâmbio comercial e nos investimentos, com impacto na logística e no transporte. Para tanto requer um estudo cuidadoso e prudente da tributação nessas searas, tanto por parte da UNASUL bem como do MERCOSUL. ${ }^{34}$ A UNASUL, deve ainda superar o processo de ratificação de seu tratado constitutivo. O MERCOSUL se baseia não apenas na vontade política dos seus países, mas também, principalmente, em um pilar fundamental para a integração produtiva: as preferências comerciais pactuadas. Por isso, a complementação entre a UNASUL e o MERSOCUL "pode contribuir para o predomínio da lógica de integração no espaço sul-americano. Tal complementação é possível. Mas vai precisar de uma liderança coletiva com a participação de todos os países da região, especialmente daqueles que valorizam um entorno regional de paz e estabilidade política" ${ }^{35}$

\section{Conclusões}

Não há dúvidas quanto a importância do Código Aduaneiro do MERCOSUL. Para a consolidação da União Aduaneira é necessário primeiramente que seja recepcionado o referido Código nos Estados Partes, mesmo considerando que não foram tratadas questôes relativas à exportação. $\mathrm{O}$ imposto de exportação poderá continuar a ser cobrado no âmbito do bloco, consequentemente continuará também sendo necessário o controle aduaneiro dessas operaçóes. Não há, portanto, que se afirmar ainda quanto a livre circulação de mercadorias.

34 No entanto, existem duas grandes diferenças. Por um lado, o MERCOSUL é uma realidade assentada em compromissos jurídicos já assumidos por seus países membros. Embora sejam compromissos imperfeitos e incompletos, seria difícil deixá-los de lado, tendo em vista as correntes de comércio e investimento que se desenvolveram entre os parceiros desde a assinatura do Tratado de Assunçáo. $\mathrm{O}$ MERCOSUL tem também uma identidade embrionária, como demonstra a incorporação da sigla nos documentos de identidade dos cidadáos dos quatro membros plenos. PEÑA, Félix. A integração no espaço sul-americano: A UNASUL e o MERCOSUL podem se complementar? In Revista Nueva

Sociedad. Diciembre de 2008. In http://www.nuso.org

35 Ibidem. 
Um dos objetivos da incidência do imposto sobre a exportação consiste em avaliar as iniciativas para a restrição do comércio no MERCOSUL, a partir de uma perspectiva econômica, política e jurídica.

É importante verificar que a retirada de gravames ou outros obstáculos são importantes para a livre circulação de bens, que é um dos objetivos fundamentais do processo de integração do MERCOSUL. E, mais importante ainda é a possibilidade da existência, no CAM, de um sistema integrado e informatizado, que em tempo real possa ter a interligação de todos os controles aduaneiros dos Estados Partes. Com isso, teriam alfândegas menos burocráticas e mais ágeis, com a diminuição de papéis e demais procedimentos administrativos tradicionais que podem ser diminuídos.

As restriçóes econômicas e não econômicas (se for o caso) não devem ser minuciosas suas previsóes no CAM. A tendência poderia ser, no mesmo sentido, considerando as proibições ou restriçóes econômicas previstas no GATT. As demais limitações devem ser respeitadas em virtude da supremacia dos tratados internacionais que prevalecem sobre as leis, no Brasil, verificado pelo controle de constitucionalidade.

Deve ser observado o caráter antieconômico do imposto sobre a exportação, que, em geral pode considerar alguns obstáculos para o país na concorrência internacional, onerando os seus produtos e o seu comércio com o estrangeiro. ${ }^{36}$

Diante desta constatação, a sua utilização há de ser feita com extrema prudência. Isto porque, ao incidir sobre produtos que serão adquiridos no exterior, a tributação pode tornar-se o mais das vezes em obstáculo para a conquista dos mercados estrangeiros. É por isso que o imposto de exportação deve incidir sobre produtos relativamente aos quais, os países exportadores apresentem tais vantagens competitivas.

Devem ser incluídas no Código Aduaneiro do MERCOSUL, se for o caso, tratativas no sentido de regulamentar as restriçóes diretas sobre a exportação, que sejam informadas as distinçóes entre restriçóes diretas e econômicas. De igual modo se regule o âmbito temporal de aplicação das proibiçóes à exportação.

36 No I Congresso Internacional de Direito Aduaneiro do MERCOSUL realizado em Buenos Aires nos dias 26 e 27/08/10, foram apresentadas as seguintes conclusóes sobre o tema das exportaçóes no âmbito do CAM: 1 - La consagración a texto expreso en el CAM de los tributos aduaneros a la exportación así como las restricciones a la exportación, sin aclaración que las mismas no son aplicables, en general, a los países miembros, son una traba a la integración del bloque com distorsiones en el mercado regional, haciendo crecer las asimetrías entre los socios. 2 - En Chile las exportaciones no pagan derechos de aduanas. En el CAM se prevé expresamente esta posibilidad. 3 - No Brasil os impostos sobre o comércio exterior podem ter alíquotas alteradas pelo Poder Executivo necessitando de alterar a Constituiçấo da Republica nos termos dos objetivos e fundamentos do MERCOSUL. 4 - El art. 157, apart. 4, del CAM prohibe la aplicación de derechos de exportación a las exportaciones intra Mercosur. Tais conclusóes foram apresentadas pelos palestrantes do Congresso conforme indicados na nota 3 . 
O CAM deveria ter por finalidade alcançar o equilíbrio dos interesses contrapostos do Estado, como controlador das exportaçóes e importaçôes e do comércio, atendendo suas necessidades. Por isso, deverá ter disposiçôes no Código que recepcionam as necessidades do comércio, sem obstrui-lo e dar garantias para evitar possíveis abusos através discricionariedade aduaneira. Ocorre que a diferença entre os países em matéria de tributos, infraçóes entre outros aspectos tributários ou não tributários, requer um estudo cauteloso. Isto porque, a finalidade de uma aduana não deveria ser arrecadatória e sim de controle da exportação e importação.

O CAM integra a legislação do MERCOSUL, portanto, deverá estar em sintonia com o Artigo $1^{\circ}$ do Tratado de Assunção, que implica na livre circulação de bens e serviços e fatores produtivos entre os países do Bloco bem como a eliminação de quaisquer direitos alfandegários, restriçóes não tarifárias, evitando com isso barreiras à circulação do mercado. No entanto, o que se observa é justamente o contrário. A cada dia são estabelecidas barreiras que impedem a circulação de bens, dificultando o processo de integração.

No caso do Código Aduaneiro, a definição do território aduaneiro para a aplicação do Código, o tratamento de áreas aduaneiras especiais e o tema dos impostos sobre a exportação têm sido os principais desafios enfrentados pelos governos, para estabelecer os acordos no nível político do Bloco.

É imprescindível a harmonização e cooperação entre as administraçóes aduaneiras para que o Código Aduaneiro do MERCOSUL se torne uma realidade e não mera ficção. Enquanto o MERCOSUL não tratar dos direitos da exportação, os Estados Partes continuarão aplicando as suas legislaçóes internas e os tratados que não contrariem o CAM.

Considerando também o processo de integração regional da UNASUL, é importante mencionar estudos que possam abranger as questóes aduaneiras com o bloco, considerando principalmente a alínea $f$ do artigo $3^{\circ}$ do Tratado Constitutivo, que destaca a integração financeira mediante a adoção de mecanismos compatíveis com as políticas econômicas e fiscais dos Estados Membros do bloco.

É salutar a necessidade de uma harmonização e cooperação entre as administraçóes aduaneiras para que o Código Aduaneiro do MERCOSUL seja realmente efetivado. Esse processo deve levar em consideração a necessidades e dificuldades típicas de países em desenvolvimento e náo deve se pautar por modelos de outros blocos, ainda que experiências como a da União Europeia possam servir de exemplos para determinadas situaçóes.

Por fim, há que se mencionar que para o sucesso da integração tanto no MERCOSUL quanto na UNASUL, é preciso vontade política dos agentes econômicos participantes do processo para resolver as questóes pendentes bem como buscar novas alternativas para a integração dos blocos. Para a eficácia e efetividade do CAM devem ser promovidas políticas convergentes para diminuir as assimetrias existentes no bloco para concretizar a União Aduaneira e alcançar o mercado comum. Os desafios são muitos. 


\section{Referências}

ACCIOLY, Elizabeth. Duas Décadas de MERCOSUL: Valeu a pena? In Revista Argumentum - UNIMAR, n. 12, 2011, p. 32/44.

AMARAL, Vivian Henriques de Mello Peixoto. O MERCOSUL e o Código Aduaneiro Comum. Ius Gentium, Curitiba, ano 4, n. 8, p. 227-240, jul./dez. 2010.

ASHIKAGA, Carlos Eduardo Garcia. Análise da Tributação na Importação e na Exportação. Editora Aduaneiras, São Paulo, 2010.

ASSIS, J. Carlos de. MERCOSUL, ataca pelas duas pontas, em 14 de maio de 2015, in http://www.ecofinancas.com/noticias/unasul-ataca-duas-pontas

BARRAL, Welbert; PIMENTEL, Luiz Otávio e CORREA, Carlos M. (org.) Direito, Desenvolvimento e Sistema Multilateral de Comércio, Fundação Boiteux, Florianópolis, 2008.

CAMPOS, Rogério Pereira de. OS CONTRAPONTOS AO MODELO UNASUL in MONÇÓES - Revista do curso de História da UFMS- campus de Coxim out.2014/mar.2015

COSTA, Lígia Maura. O Código Aduaneiro do MERCOSUL. In MERCOSUL. Seus efeitos Jurídicos, econômicos e políticos nos Estados-Membros. 2a ed. Porto Alegre, Livraria do Advogado, 1997.

COSTA, Lígia Maura. Os Códigos Aduaneiros do MERCOSUL e da Uniáo Europeia:

Ficção vs. Realidade. In Contratos Internacionais e Direito Econômico no MERCOSUL. São Paulo. LTR, 1996.

FERNANDES, Edison Carlos. Sistema Tributário do MERCOSUL, 3a edição. São Paulo. Editora revista dos Tribunais, 2001.

FREITAS, Maxsoel Bastos de. O Direito Aduaneiro como ramo autônomo do Direito. v.3, n.3, Uruguaiana, RS: Revista do Direito- Periódico PUCRS, 2003.

FREITAS, Vladimir Passos de. Importação e Exportaçáo no Direito Brasileiro. São Paulo: Revista dos Tribunais, 2004.

GADELHA, Regina Maria A. F. (org.). MERCOSUL a UNASUL - Avanços do Processo de Integração. São Paulo, EDUC FAPESP, 2013.

Informe MERCOSUL no $14-2^{\circ}$ sem./2008 e $1^{\circ}$ sem./2009, CNI.

LABRANO, Roberto Ruiz Díaz. Unión Aduanera em el MERCOSUR. Nuevos desafíos para las Administraciones Aduaneras y Operadores ADUA. Revista do Centro de Desp. de Aduana del Paraguay, www.cdap.org.py/wp-content/uploads/2012/04/16_pdfsam_revista-julio-20111.pdf, p. 30/32. 
MARINELLI, Caludia M. M. e Jorge Luis Tosi. Código Aduanero del Mercosur (anotado), Editorial Zavala, Argentina. 2013.

MAZZUOLI, Valerio de Oliveira; GOMES, Eduardo Biacchi (organizadores). Direito da Integração Regional. Diálogo entre Jurisdiçóes na América Latina. Saraiva, São Paulo, 2015.

MEIRA, Liziane Angelotti. Integração Regional e Tributos sobre o comércio exterior no MERCOSUL, in Revista da PGFN, Ano 1, n. 2, 2011, p. 53/71.

MEIRA, Liziane Angelotti. Reflexóes sobre o Código Aduaneiro do MERCOSUL. In Revista de Direito Internacional Econômico e Tributário RDIET, Brasília, V. 6, no 2, p. 259-290, Jul-Dez, 2011.

PATRICIO, Mariza Giacomin Lozer. O processo de integraçáo do MERCOSUL: particularidades e atualidades in Direito \& Justiça, Porto Alegre, v. 39, n. 1, p. 4147, jan./jun. 2013.

PEÑA, Félix. A integração no espaço sul-americano: A UNASUL e o MERCOSUL podem se complementar? In Revista Nueva Sociedad. Diciembre de 2008. http:// www.nuso.org

PEROTTI, Alejandro Daniel. Mercosur: Código Aduanero y derechos de exportación. 18 de octubre de 2010, in www.regionnortegrande.com.ar/?articulo=2145

PIRES, Adilson Rodrigues. Código Aduaneiro do MERCOSUL - Comentários ao Protocolo. São Paulo. Editora Aduaneiras, 1999.

RABELO, Felipe Cesar José Matos. A Coexistência MERCOSUL-UNASUL, in Revista SJRJ, Rio de Janeiro, v. 18, n. 30, p. 55-68, abr. 2011.

ROCHA, Maria de Conceição Ramos. MERCOSUL - Alcances da Uniáo Aduaneira no Ordenamento Jurídico Brasileiro. Rio de Janeiro. Editora L. Juris, 1999.

SOARES FILHO, José. MERCOSUL: surgimento, estrutura, direitos sociais, relação com a UNASUL, perspectivas de sua evolução. Revista CEJ, Brasília, Ano XIII, n. 46, p. 21-38, jul./set. 2009.

TOMAZETTE, Marlon. Comércio Internacional \& Medidas Antidumping. Curitiba: Juruá, 2008.

TREVISAN. Rosaldo. Temas Atuais de Direito Aduaneiro. Lex Editora, São Paulo: 2008. 